\title{
COORDINATING THE INSTRUCTION OF FOUR ONLINE COURSES
}

\author{
Seach Chyr (Ernest) Goh, Jannik Haruo Eikenaar, Mehran Shirazi \\ University of British Columbia, Okanagan Campus \\ Corresponding Author E-mail Address: ernest.goh@ubc.ca
}

\begin{abstract}
Extended Abstract - The University of British Columbia Vantage College offers a pathway for academically qualified international students who do not yet meet the English language admission requirements for direct entry into UBC. In the summer of 2020, during the COVID-19 pandemic, we taught four courses to a cohort of 64 students scattered across the globe. The courses were taught online and asynchronously, raising coordination challenges in terms of class schedule and delivery, assessment, and student support. To address those challenges, we developed a highly structured weekly schedule, specifying lecture and assessment days, as well as regular, synchronous office hours.

We met weekly to keep each other updated about the progress of students. Students falling behind in multiple courses were reported in an "early alert" system: a university-specific resource through which students are contacted by health and wellness staff.

A midterm survey was conducted and the feedback was generally positive. Final results in the courses were varied, with some comparable to previous cohorts while some much better.
\end{abstract}

Keywords: multiple course coordination, asynchronous, online design course.

\section{INTRODUCTION}

The UBC Vantage College programme is an elevenmonth, Year One course of study program divided into three terms which adds English language instruction to the usual first-year courses. Upon successful completion, students progress into the second year of their chosen undergraduate degree. It is available for Arts, Science, and Applied Science (engineering) programs. For the engineering program, Terms 1 and 2 are taught on the Vancouver campus, and Term 3 (the summer term) is taught on the Okanagan campus. In 2019-20, students resided on the Vancouver campus for Term 1 and part of Term 2 but in the summer, some students had returned to their home countries/hometowns or did so during the term while others remained in the lower mainland of $\mathrm{BC}$. Therefore, Term 3 was delivered completely online to the 64 students in the engineering program. Their geographical distribution comprised 37 in $\mathrm{BC}$, declining to 32 at the end of term, 4 in Afro-Eurasia, 19 in East Asia, increasing to 24, and 4 in other Canadian provinces and Mexico. Given the wide distribution and range of time zones, the instructors decided to offer the entire term asynchronously.

Ample literature exists on flipped and online learning [1]. An instructor delivering a single online course in isolation certainly has a clear overview of the learning activities for his/her course. This is probably displayed as calendar entries in his/her institution's learning management system. The students' perspective for a term of four concurrent courses multiplies those calendar entries by four, with the potential for poor workload distribution. This paper describes the planning of four online courses to make the learning experience more manageable.

\section{CURRICULUM}

Term 3 is an 8-week term. The courses offered in Term 3 are:

1. VANT 151 multidisciplinary design project,

2. APSC 176 engineering communication,

3. APSC 179 linear algebra for engineers, and

4. APSC 180 engineering mechanics: statics.

VANT 151, the project course, originally required prototype fabrication. In this run, a hybrid project work model was adopted. Each project team had 10 to 13 students, divided into 5 to 6 sub-teams responsible for different aspects of the project. Students in the electrical/electronic and user-interface (firmware) subteams had a kit of electronic components delivered to their homes for actual prototyping. Students in other sub-teams created CAD models and ran simulations/visualisations of their designs.

APSC 176, the communication course, was delivered via lectures and included assignments completed individually and in pairs.

Writing support was provided for the project course and engineering communication by Academic English instructors who had taught the students in earlier terms. 
These instructors offered sign-up sessions for students to review drafts of reports, project web pages, and a variety of other written assignments.

APSC 179, the linear algebra course was delivered in eight weekly modules. Each module consisted of three videos that covered linear algebra theory, three problemsolving videos, one assignment, and one quiz. Subtitles were prepared for all the videos to assist the students to follow the instructions more easily. The problem-solving videos covered the applications of linear algebra in engineering and guided the students to understand a problem and approach it using the correct method step-bystep. The assignment and quiz in each module covered the videos of the module in the previous week. The purpose of the quiz was to make sure students were following the videos, and the purpose of the assignment was to give them more problems to practice. The due dates of the assignments and quizzes were fixed every week and were selected in coordination with the assessments of the other three courses.

APSC 180, the statics course, is normally delivered via lectures for the whole cohort, and tutorials for smaller class sizes of about 30 students. In this run, media were produced, with different focus for lectures and for tutorials. Lecture media explain the theory and guide students through solving introductory questions that illustrate the application of the theory. Typically, one to two questions are covered in each topic. Such lecture activities are intended to foster active learning [1]. The course content is divided into twenty-one topics, so students are expected to cover roughly three topics per week. Tutorial media explain the solution to tutorial questions that are more challenging and/or adapted from real-life applications. Typically, each piece of media covers about ten long questions involving comprehensive calculations, occasionally with a few multiple-choice questions on theoretical concepts, intended to be completed in a week.

\section{COORDINATION}

The instructor for VANT 151 and APSC 180 was also the coordinator of the Okanagan campus portion of the programme. The coordinator led several meetings with the other two instructors to explore approaches to the term and liaised with both Vancouver colleagues and Vantage College students.

Table 1: Geographical locations and time zones.

\begin{tabular}{|c|c|c|}
\hline Location & Time Zone & $\begin{array}{c}\text { No. of } \\
\text { Students }\end{array}$ \\
\hline BC & -7 & 37 \\
\hline Other Canadian, Mexico & -6 to -4 & 4 \\
\hline Afro-Eurasia & +2 to +4 & 4 \\
\hline East Asia & +7 to +9 & 19 \\
\hline
\end{tabular}

In considering how to best deliver the courses, the geographical locations and time zones of students were tabulated as shown in Table 1.

Next, the times in representative geographical locations covering the spread of time zones were tabulated, and the unreasonable hours (12 am to $6 \mathrm{am}$ ) were identified, as shown in Table 2.

With this overview of world times, it was clear that the only time suitable for synchronous activities was $6-8$ am Pacific Daylight-saving Time (PDT), and even then, marginally so both for students based in BC and South Korea. With just two suitable hours a day, this situation drove us to make the fundamental decision to deliver our courses mainly asynchronously, perhaps with the possibility of a few synchronous sessions where it was pedagogically desirable.

Table 2: Reasonable hours by region.

\begin{tabular}{|c|c|c|c|}
\hline $\begin{array}{c}\text { BC PDT } \\
(-7)\end{array}$ & $\begin{array}{c}\text { East. Canada } \\
(-4)\end{array}$ & $\begin{array}{c}\text { NA/ME } \\
(+2 /+4)\end{array}$ & $\begin{array}{c}\text { Korea } \\
(+9)\end{array}$ \\
\hline $6 \mathrm{am}$ & $9 \mathrm{am}$ & $3 / 5 \mathrm{pm}$ & $10 \mathrm{pm}$ \\
\hline $8 \mathrm{am}$ & $11 \mathrm{am}$ & $5 / 7 \mathrm{pm}$ & $12 \mathrm{am}$ \\
\hline $10 \mathrm{am}$ & $1 \mathrm{pm}$ & $7 / 9 \mathrm{pm}$ & $\mathbf{2} \mathbf{~ a m}$ \\
\hline $12 \mathrm{pm}$ & $3 \mathrm{pm}$ & $9 / 11 \mathrm{pm}$ & $\mathbf{4} \mathbf{~ a m}$ \\
\hline $2 \mathrm{pm}$ & $5 \mathrm{pm}$ & $\mathbf{1 1} \mathbf{p m} / \mathbf{1} \mathbf{~ a m}$ & $6 \mathrm{am}$ \\
\hline $4 \mathrm{pm}$ & $7 \mathrm{pm}$ & $\mathbf{1 / 3} \mathbf{~ m}$ & $8 \mathrm{am}$ \\
\hline $6 \mathrm{pm}$ & $9 \mathrm{pm}$ & $\mathbf{3 / 5} \mathbf{~ m}$ & $10 \mathrm{am}$ \\
\hline $8 \mathrm{pm}$ & $11 \mathrm{pm}$ & $\mathbf{5 / 7} \mathbf{a m}$ & $12 \mathrm{pm}$ \\
\hline $10 \mathrm{pm}$ & $\mathbf{1} \mathbf{a m}$ & $7 / 9 \mathrm{am}$ & $2 \mathrm{pm}$ \\
\hline $12 \mathrm{am}$ & $\mathbf{3} \mathbf{a m}$ & $9 / 11 \mathrm{am}$ & $4 \mathrm{pm}$ \\
\hline
\end{tabular}

NA/ME: North Africa/Middle East

Next, the instructors considered how best to encourage students to schedule their work rather than compressing it into one or two days per week. With four courses to handle, including a project, there was also the concern that students may not balance their effort for each course well. To support students in managing their efforts, and for us to keep track of their progress, we decided to set weekly goals in every course. Each course had a set of small goals and a set of large goals. Most of the small goals lay the foundation for or build up to the large goals. Therefore, it was desirable to have small goals due before the large. On that basis, we chose Tuesday to Friday as staggered deadlines for large goals. By deciding to set the small goals to be two days before the large, Mondays to Wednesdays became the deadlines for small goals. Finally, for the project course, VANT 151, the small goals were due on Thursdays, with the intention that they support completion of the large goal in the following week. The distribution of goal deadlines is shown in Table 3.

To support students in completing these goals, we all held regular office hours. These were scheduled after the deadlines for small goals, with the rationale that students would have a better understanding at that point of their 
Table 3: Timetable of deadlines.

\begin{tabular}{|c|c|c|c|c|c|}
\hline & Monday & Tuesday & Wednesday & Thursday & Friday \\
\hline Small goals & APSC 176 & APSC 179 & APSC 180 & VANT 151 & \\
\hline $\begin{array}{c}\text { Office hours } \\
10: 00-12: 00\end{array}$ & VANT 151 & APSC 176 & APSC 179 & APSC 180 & \\
\hline 18:00-20:00 & & VANT 151 & APSC 176 & APSC 179 & APSC 180 \\
\hline Large goals & &
\end{tabular}

Table 4: Small and large goals.

\begin{tabular}{|c|l|l|}
\hline Course & \multicolumn{1}{|c|}{ Small Goals } & \multicolumn{1}{c|}{ Large Goals } \\
\hline VANT 151 & Quizzes, peer evaluations, log book & CAD exercises, parts of reports and presentation slides \\
\hline APSC 176 & Low-stakes assignments completed in pairs & Higher-stakes assignments completed individually \\
\hline APSC 179 & Quizzes & Assignments \\
\hline APSC 180 & Lecture activities & Tutorials \\
\hline
\end{tabular}

goal-specific competencies, and that students would have time to get the support needed to complete the large goals.

As shown in Table 3, this arrangement produced a systematic roadmap for students to manage their time toward the completion of all their courses.

For convenience of students in East Asia, one of the office hour slots was in the evening. The goal deadline was always 9 pm PDT, which was reasonable for most students except those in Afro-Eurasia, when it would be early morning. So, for the 4 students in Egypt, Turkey, Russia and Saudi Arabia, their due time was 2 am PDT the following day.

This timetable of deadlines, rather than the traditional timetable, was communicated to students at the beginning of term. It was emphasised to them that they should plan their own personal timetable to complete the goals on schedule.

Special arrangements were made for holidays: week 2 with Victoria Day, and week 8, the final week of the term, which is the week of Canada Day. The office hours affected by the holidays were moved to Friday and the corresponding goals moved to Saturday. In week 2, the term had just started and not a lot of content had been covered, so we could afford to cancel the large goals, while for week 8, students were completing culminating work and so small goals were not needed.

The types of small and large goals are listed in Table 4. In order not to overwhelm students, goals were published periodically, typically one to two weeks before deadlines.

Additionally, the project course VANT 151 had two synchronous sessions. The first was a lecture on design synthesis and evaluation, which involved activities in breakout sessions in their project teams, while the second was an oral presentation with questions and answers. It was felt that having these sessions synchronously would foster the connection among teammates and allow assessment of the spontaneity of response and hence infer the level of involvement of each student in the team's effort, respectively.

We pre-recorded media for lectures, tutorials and studios (equivalent to labs), some with the assistance of TAs. They were typically published prior to the start of the week during which they were intended to be used.

With our plan in place, we went ahead and ran the term. We had weekly meetings during which we checked with each other about students who were falling behind in multiple courses. We reported such students through the university's "early alert" system. It is a web form for any instructor to enter the details of a potential issue with a particular student such as poor academic performance, mental health, etc. The information is routed to advising staff who follows up on them and if necessary, further refers them to health and wellness support. In spite of our efforts, one student fell behind late in the term but was not detected and failed three courses. We acknowledge that there is time lag from observing consistently poor performance in assignments, to raising the issue during the instructors' meeting, to entering the case into the early alert system, to the advisor contacting the student, and finally to the student responding. Given the short 8 -week term, it is probably difficult to support those falling behind in the final two or even three weeks. There were other students who fell behind in single courses, but in those cases, we left it to the instructor of the relevant course to follow up directly with the student.

The coordination of assessments was simplified somewhat by the elimination of some midterm exams. Originally, the project and communications courses did not have midterm exams. In this run, permission was obtained to eliminate midterm exams for linear algebra and statics as well. The rationale was:

1. It would have been more resource intensive since two sessions of exams would have to be conducted. 
2. Online invigilation might be difficult for students overseas due to unreliable internet connection.

3. Without reliable invigilation, an accepted good practice for reducing the temptation to commit academic dishonesty is to reduce high stakes assessments. [2]

Therefore, the implemented in-term assessments were the various large and small goals. Both courses had online examinations in the week after the end of classes, on Tuesday for statics and Friday for linear algebra, thus giving students the maximum study time for each course from the end of term.

In the communication course, which does not traditionally include a midterm or final exam, the most significant assessment adjustment was the use of weekly, paired assignments: these were designed to partially compensate for the lack of synchronous student interaction, and they also served to scaffold students' skill development.

For the statics course, the instructor cautions against making direct comparison of exam results with those of the previous year. Although the average course mark was significantly better than previous year, at about 7 percentage points higher, this is attributed to the exam being comprised of all multi-part multiple-choice questions which inherently guided the problem-solving process. In previous years, two questions were long questions which required students to form their own problem-solving strategy.

For the other three courses, success and failure rates were similar to those of previous cohorts, including both the pass/fail rates and the average course marks.

\section{FEEDBACK}

We requested our Centre for Teaching and Learning conduct a midterm survey with these three questions:

1. What has been helpful? That is, what should your instructors keep doing?

2. What has not been helpful? That is, what should your instructors stop doing?

3. What else would be helpful?

Feedback was generally positive. Selected positive student comments include:

The professor has explained different problems and how to solve them, which helps students to review their answers.

The PowerPoint is clear and easy to understand.

Having the pre-recorded lectures helps students to watch these lectures whenever they can and if something is difficult to understand, re-watching these videos can help.

The studio videos that demonstrate the procedure of Solidworks (has been helpful).
Negative feedback was typically on non-pedagogical matters such as: poor sound quality in the recorded lectures, too much work (a comment that is not limited to this version of the program), more time for quizzes, unclear $x$ (which can be found in the syllabus). For the project course, there was a sentiment among respondents that it was too open ended, exemplified by these comments:

Honestly, I feel like I am getting lost in this course but still have some sense of what to do.

Having a lecture which explains most of the project itself. Some students are not sure what they need to achieve in detail about this project.

Give an exact workload and task table for each subteam.

For APSC 176, several students commented on the usefulness of the paired assignments in helping them maintain connections with their peers as well as practice specific communication tasks before completing them in the higher-stakes large goals.

The takeaways from these feedback are:

1. Students appreciate the ability to re-watch particular segments of pre-recorded lessons. This is consistent with the earlier findings of the statics instructor [3].

2. During pre-pandemic times, the project course instructor had observed that students of this program, being all learners of English as a second language, took more than the recommended time to complete Solidworks tutorials when relying on written guides. The use of animated media with narration this term was helpful.

3. Project work in an online, asynchronous mode of delivery requires more structured guidance, especially for students in lower years.

4. Include learning activities that encourage social connection among peers.

\section{IMPACT ON INSTRUCTORS}

The first impact of the decision to offer all courses asynchronously was a massive increase in instructor workload. As the reader may agree, the time it takes to prepare a pre-recorded online lesson can be typically ten times the duration of the recording. The statics course benefitted from a project that had co-op students assisting with the production of media. A 4-month co-op term (more than 400 hours) produced media for 11 lectures (16.5 hours). Even if niceties are dispensed with for the sake of expediency, production time is still several multiples of class time. We feel that the transition to online teaching for the pandemic is a good opportunity to formally recognise the effort of lesson preparation as distinct from the timetabled hours that an instructor has to appear in front of the class or on Zoom. Simply measuring workload by the 
number of timetabled lecture hours does not truly reflect the contributions of an instructor.

However, we hope that these pre-recorded lessons can be re-used in future if the pandemic persists, or used as supplementary materials if in-person teaching resumes. Additionally, they lay the foundation for exploiting new opportunities such as education for remote regions, creation of new open educational resources, etc.

Against that backdrop, we found that working together to plan the coordinated delivery of the courses and then meeting regularly throughout the term provided opportunities for social and professional engagement. The situation could have been worse if each of us had been slogging in isolation.

We also found that weekly discussions of students' successes and challenges improved attention to student progress. We were able to better identify students who were struggling in the program (i.e., not just in individual courses) and to plan adjustments to deadlines and assignment requirements based on informal assessments of student workload and stress.

We feel that the "timetable of deadlines" improved clarity for the students regarding how learning outcomes were scaffolded in the courses and program. The recurring small goal-large goal sequence made it clearer to students how they should develop and apply the skills and knowledge required.

This timetable also improved division of responsibilities among instructors, TAs, and auxiliary instructors. Planning, delivering, and assessing the small and large goals made it easier for instructors and TAs to assume distinct responsibilities (and avoid overlap) as well as for auxiliary instructors to supplement course-based instruction.

\section{CONCLUSION}

Coordinating the planning, delivery, and assessment of the four courses across Term 3 was tremendously successful. It avoided many of the problems that we identified before the term began: namely, how to foster student engagement, how to maintain a sense of community, and how to effectively support students across locations and time zones. Although student grades were mostly unchanged from previous cohorts, they are meant to measure attainment of learning outcomes rather than problems with remote delivery. The fact that grades were unchanged suggests that the quality of instruction was as good as in-person delivery.

From the instructors' perspective, the coordination also helped to maintain good spirits during those very challenging times.

The coordination required significant commitment from all instructors. Initial discussions, where a wide variety of approaches and options were on the table, were quite long and complex. As we narrowed down to the final implementation and got into the routine of running our courses, we quickly reached a tipping point where our discussions were shorter and more focused.

Looking ahead to this year's Term 3, which promises to be similar to last year's, an additional resource that we shall be harnessing is the experiences of the Term 1 and 2 instructors who have been teaching remotely. Given the success of coordination last year, we shall similarly coordinate our work and incorporate their experiences in our course and term design.

\section{References}

[1] E. Marasco, M. Moshirpour, M. Moussavi, L. Behjat and Y. Amannejad, "Evidence-based Best Practices for First-year Blended Learning Implementation," in Proceedings of the ASEE Conference, Salt Lake City, 2018.

[2] S. Freeman, S. L. Eddy, M. McDonough, M. K. Smith, N. Okoroafor, H. Jordt and M. P. Wenderoth, "Active learning boosts performance in STEM courses," in Proceedings of the National Academy of Sciences, 2014.

[3] UBC Okanagan Office of the Provost and VicePresident Academic, "Assessment Strategies to Reduce Academic Misconduct," [Online]. Available: https://provost.ok.ubc.ca/initiatives/onlinetransition/faculty-resources/faculty-resources-foracademic-integrity/assessment-strategies-to-reduceacademic-misconduct/. [Accessed 8 March 2021].

[4] S. C. Goh, Y. Yan and J. Hopkinson, "Effectiveness of Media Modules for Blended Delivery of a Statics Course," in ASEE Conference, Virtual, 2020. 